\title{
A New Recycling Process of Waste Glass Wool Using Pyrolysis with Sodium Hydroxide
}

\author{
T. Wajima and S. Matsuka
}

\begin{abstract}
Glass wool insulation consists of glass fibers and phenolic resin as a binder to be a texture similar to wool, resulting in high thermal insulation properties. A large amount of them were used for energy conservation of buildings, and recently disposed at landfill sites to be pressured because of large volume to mass. In this study, we attempted to convert resin and glass fiber in the waste glass wool into gas and water glass using sodium hydroxide reaction, respectively. Waste glass wool was cut, sample peace $(1 \mathrm{~g})$ and sodium hydroxide $(1-3 \mathrm{~g})$ put into the reactor, and the reactor was heated with an electric furnace while flowing nitrogen $(50 \mathrm{~mL} / \mathrm{min})$. After heating to setting temperature $\left(400-550{ }^{\circ} \mathrm{C}\right)$ for $1-30 \mathrm{~h}$, the reactor was naturally cooled to room temperature. The generated gas during the reaction was collected by gas pack. After cooling, the residue inside the reactor was washed with nitric acid, filtrates to obtain the residual substance, and silica concentration in the filtrate was measured to calculate the silica extracted content from waste glass wool. By using pyrolysis with sodium hydroxide, waste glass wool can be decomposed by converting the resin into the gases, such as hydrogen and methane, and glass fiber into soluble salt to be extracted into the solution. Waste glass wool can be decomposed by pyrolysis with 3 times weight of $\mathrm{NaOH}$ to the sample above $400{ }^{\circ} \mathrm{C}$ for $1-6 \mathrm{~h}$.
\end{abstract}

Index Terms - Waste glass wool, sodium hydroxide, pyrolysis, silica extraction.

\section{INTRODUCTION}

The Tokyo Olympic Games will be held in 2020, and the number of renovation works is expected to increase, concerning the increase of waste heat insulating materials as construction waste.

Glass wool insulator is a typical heat insulating material used in Japan. Glass wool insulation consists of glass fibers and phenolic resin as a binder to be a texture similar to wool with many small pockets of air between the glass, and these small air pockets result in high thermal insulation properties. Approximately two hundred thousand tons per year of glass wool waste are disposed from the construction site and the production factory of glass wool [1]. In recycling of glass wool waste, phenolic resin included in glass wool deteriorates glass quality and makes the operation of a smelting furnace uncertain [2]. Therefore, a large quantity of glass wool waste is disposed of as an industrial waste. Since the glass wool insulation material has a large volume to mass, the capacity of landfill site is put pressure, and development of new recycling technology is desired.

In our previous studies, waste plastics was converted into

Manuscript received February 10, 2019; revised May 7, 2019.

Takaaki Wajima is with the Department of Urban Environment Systems, Graduate School of Engineering, Chiba University, Japan (e-mail: wajima@tu.chiba-u.ac.jp). oil and gas by pyrolysis with $\mathrm{NaOH}$ to promote the decomposition of plastic resin [3], [4]. On the other hands, inorganic silicate by-products, such as waste cake, slag, waste porcelain and waste glass, can be converted into soluble sodium silicate by heating with $\mathrm{NaOH}$ (alkali fusion) to synthesize functional materials, such as zeolites, layered double hydroxides and so on [5]-[16]. Furthermore, composite materials including organic materials and inorganic silicates, such as mold resin, glass fiber rein-forced plastics and bamboo, were pyrolysed with $\mathrm{NaOH}$, and the contents of organics and inorganics can be converted into fuel gases $\left(\mathrm{H}_{2}\right.$ and $\left.\mathrm{CH}_{4}\right)$ and soluble silicate to be extracted into acid solution, respectively [17]-[19]. Waste insulator is composite materials including organic resin and inorganic glass fibers, and can be converted to be recycled by pyrolysis with $\mathrm{NaOH}$.

In this study, we tried a new recycling technology of waste glass wool insulation material using pyrolysis with $\mathrm{NaOH}$. By using sodium hydroxide, removal of gasification of phenolic resin by catalysis of sodium hydroxide and conversion of glass fiber into sodium silicate by reaction of sodium hydroxide. The gas is used as a fuel, and the sodium silicate salt is dissolved in an aqueous solution and recovered as a silicic acid component (silica component). We examined the pyrolysis conditions of waste glass wool insulation for this recycling technology.

\section{EXPERIMENTAL}

\section{A. Waste Glass Wool}

The sample used in this study is waste glass wool obtained from one of the intermediate treatment contractors in Japan. Waste glass wool mainly composed of $95 \%$ of inorganic contents (glass fiber, etc.) and $5 \%$ of organic contents (phenol resin, etc.), and was cut for use as a sample as shown in Fig. 1.

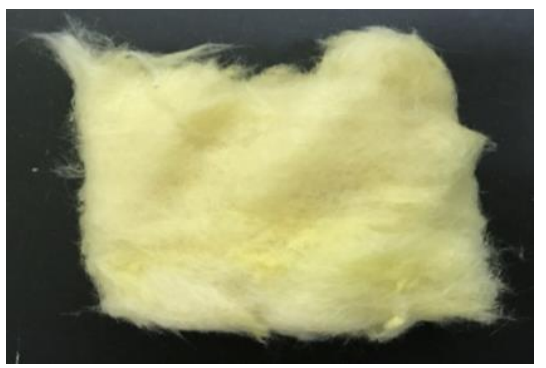

Fig. 1. Photo of waste glass wool sample.

\section{B. Experimental Procedure}

The experimental apparatus is shown in Fig. 2. Waste glass 
wool $(1 \mathrm{~g})$ and $\mathrm{NaOH}(0-3 \mathrm{~g})$ put into the reactor, and heated to setting temperatures $\left(400-550{ }^{\circ} \mathrm{C}\right)$ with an electric furnace while flowing nitrogen $(50 \mathrm{~mL} / \mathrm{min})$ for $2.5 \mathrm{~h}$. After heating to setting temperature (reaction temperature), the reactor was heated for $1-30 \mathrm{~h}$ (heating time), and then naturally cooled to room temperature. Since the residual substance was included in fused salt solid, it dissolves in 100 $\mathrm{mL}$ of $1.5 \mathrm{~mol} / \mathrm{L}$ nitric acid, and filtrates to obtain the residual substance in the reactor. After filtering, the residue remaining on the filter paper was observed, and the weight of the residue was measured to calculate residual weight ratio. The amount of silicon extracted into the filtrate was analyzed by atomic absorption spectrophotometers (AAnalyst200, Perkin-Elmer). During the experiment, the gas generated in the reactor pass through the water bubbling bottle to capture the halogen content in the gas, and then the passing gas was collected in gas pack. The collected gas was analyzed by a gas chromatograph (GC-2014ATF, SHIMADZU). It is noted that little amount of pyrolysis oil can be obtained on all experimental conditions.

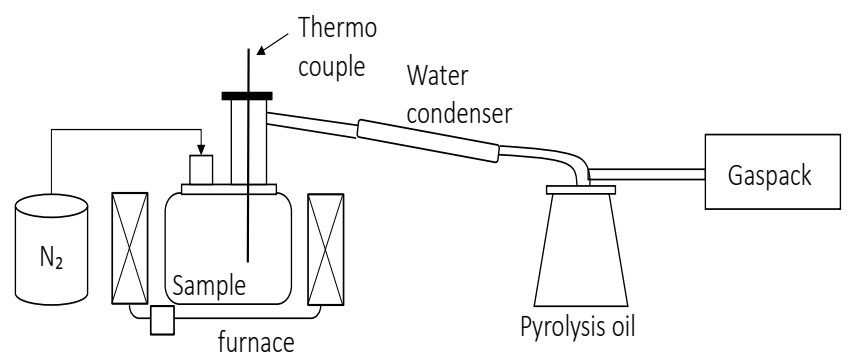

Fig. 2. Experimental apparatus for this experiment.

\section{RESUlTS AND DisCUSSION}

Fig. 3 shows the photos of the residues with various $\mathrm{NaOH}$ addition. The heating time is $1 \mathrm{~h}$ and the reaction temperature is $400{ }^{\circ} \mathrm{C}$. Without addition of $\mathrm{NaOH}$, waste glass wool could not be decomposed and remained wool shape with glass fiber can be of observed (Fig. 3(a)). With addition of $\mathrm{NaOH}$, the mixture of wool shape glass and powder were observed in the residues with $\mathrm{NaOH}$ addition of $1 \mathrm{~g}$ and $2 \mathrm{~g}$ (Fig. 3 (b), (c)), and only powder residue was observed in the residue with $\mathrm{NaOH}$ addition of $3 \mathrm{~g}$ (Fig. 3 (d)), due to the decomposition of both resin and glass fiber by pyrolysis with $\mathrm{NaOH}$.
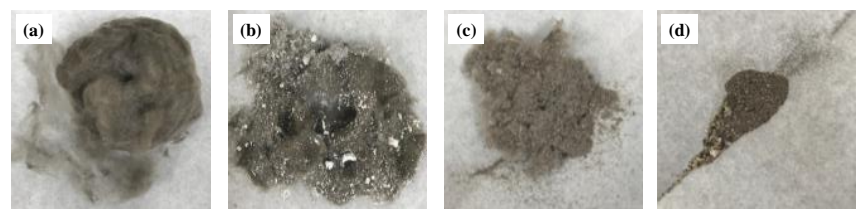

Fig. 3. Photos of the residue after the reaction with addition of $\mathrm{NaOH}$; (a) $0 \mathrm{~g}$, (b) $1 \mathrm{~g}$, (c) $2 \mathrm{~g}$ and (d) $3 \mathrm{~g}$.

Fig. 4 shows the residual weight ratio of the residue after pyrolysis with $\mathrm{NaOH}$. While almost $100 \%$ weight of raw sample was remained by pyrolysis without $\mathrm{NaOH}$, the residue weight decreases by pyrolysis with $\mathrm{NaOH}$. With increasing the $\mathrm{NaOH}$ addition, residual ratio decreases, and the residue with $3 \mathrm{~g}$ of $\mathrm{NaOH}$ addition has one-fifth weight than raw sample.

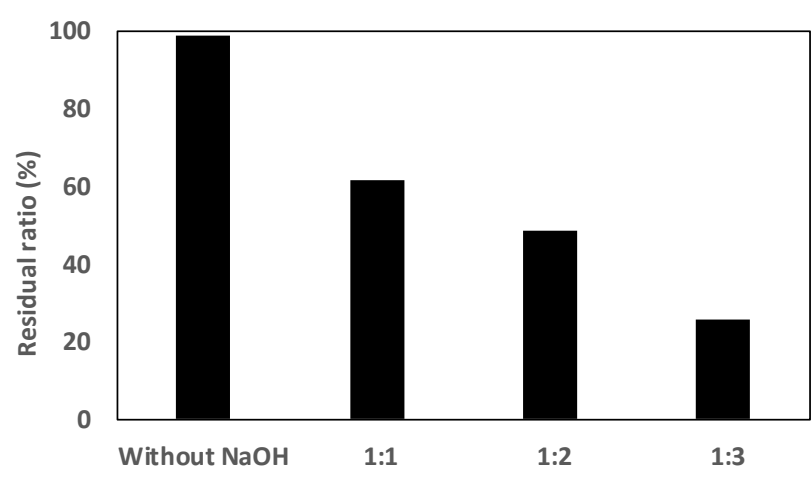

Fig. 4. Residual weight ratios of the residue after the reaction with various addition of $\mathrm{NaOH}$.

Fig. 5 shows the product gas during the experiment with various amount addition of $\mathrm{NaOH}$. Production of gas without $\mathrm{NaOH}$ is lower than those with $\mathrm{NaOH}$. Production of hydrogen gas and methane gas was confirmed, and that increased with increasing sodium hydroxide addition.

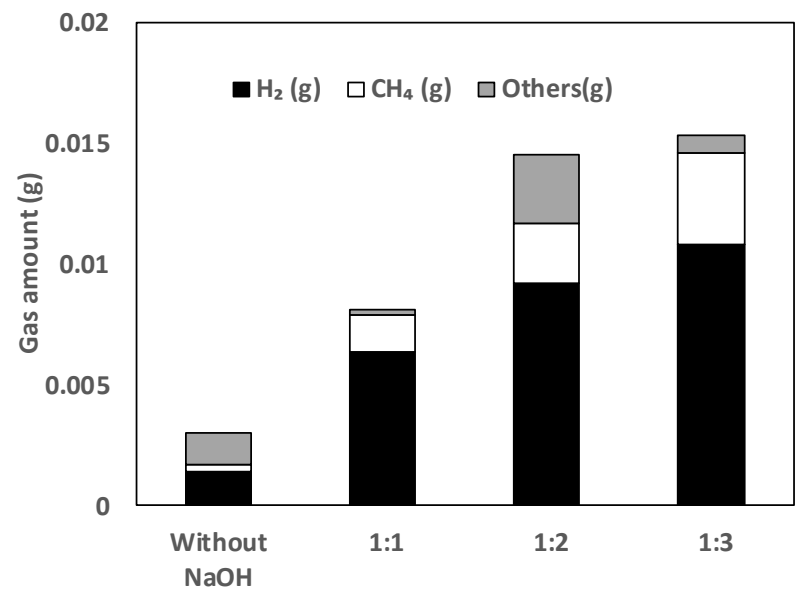

Fig. 5. Product gas during the pyrolysis with various addition of $\mathrm{NaOH}$.

Fig. 6 shows $\mathrm{SiO}_{2}$ content extracted from the residue after the pyrolysis. While $\mathrm{SiO}_{2}$ content could not be extracted from the residual after the pyrolysis without $\mathrm{NaOH}, \mathrm{SiO}_{2}$ content could be extracted from the residue after the pyrolysis with sodium hydroxide. With increasing $\mathrm{NaOH}$ addition, a larger amount of $\mathrm{SiO}_{2}$ can extracted into the solution.

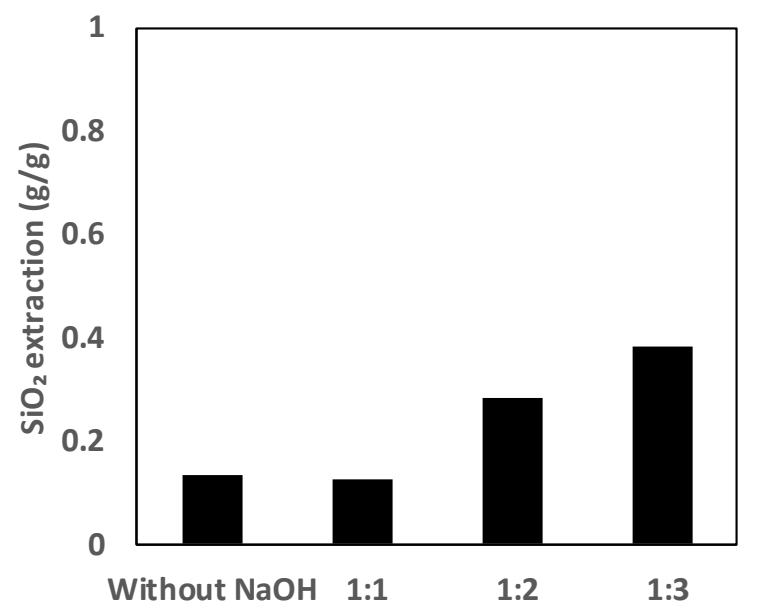

Fig. 6. $\mathrm{SiO}_{2}$ extraction from the residue after the pyrolysis with various addition of $\mathrm{NaOH}$ 
Therefore, the weight of waste insulator was reduced by decomposing the resin into gas and extracting the glass fiber into acid solution by pyrolysis with $\mathrm{NaOH}$.

Fig. 7 shows the photos of the residue after the pyrolysis with $\mathrm{NaOH}$ for various heating times. The reaction temperature is $550{ }^{\circ} \mathrm{C}$ and $\mathrm{NaOH}$ addition is $3 \mathrm{~g} / \mathrm{g}$. At all reaction times, decomposition of both resin and glass fiber was observed (Fig. 7). It is noted that the residues after 30-h heating are granules with brown color.
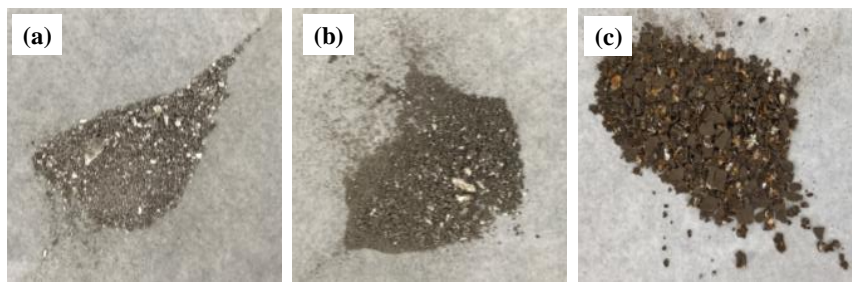

Fig. 7. Photos of the residue after the reaction with addition of $\mathrm{NaOH}$ for (a) $1 \mathrm{~h}$, (b) $6 \mathrm{~h}$ and (c) $30 \mathrm{~h}$.

Fig. 8 shows the residual weight ratio after the pyrolysis for various heating times. Residual ratios after the heating for $1 \mathrm{~h}$ and $6 \mathrm{~h}$ are approximately $20 \%$, respectively, while that for $30 \mathrm{~h}$ is about $70 \%$.

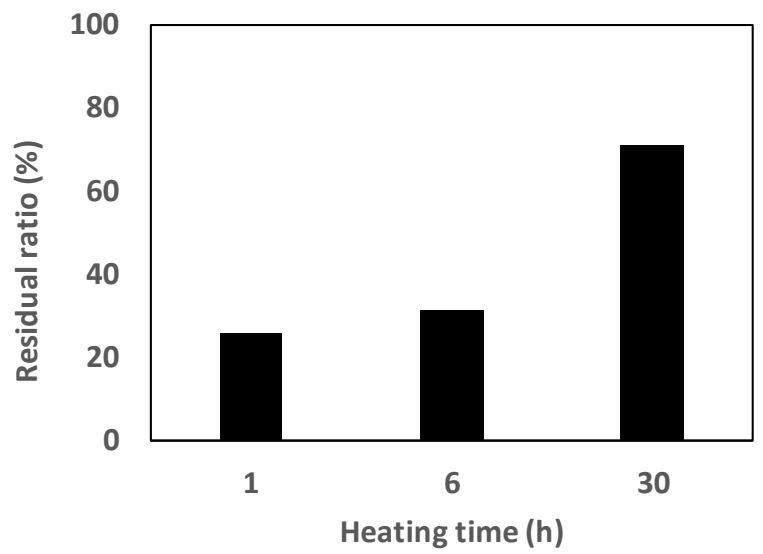

Fig. 8. Residual weight ratios of the residue after the reaction with addition of $\mathrm{NaOH}$ for various heating times.

Fig. 9 shows the product gas by pyrolysis with $\mathrm{NaOH}$ addition for various heating times. Production of hydrogen gas and methane gas was confirmed by pyrolysis with sodium hydroxide for both $1 \mathrm{~h}$ and $6 \mathrm{~h}$, while a larger amount of hydrogen gases was generated after $30 \mathrm{~h}$.

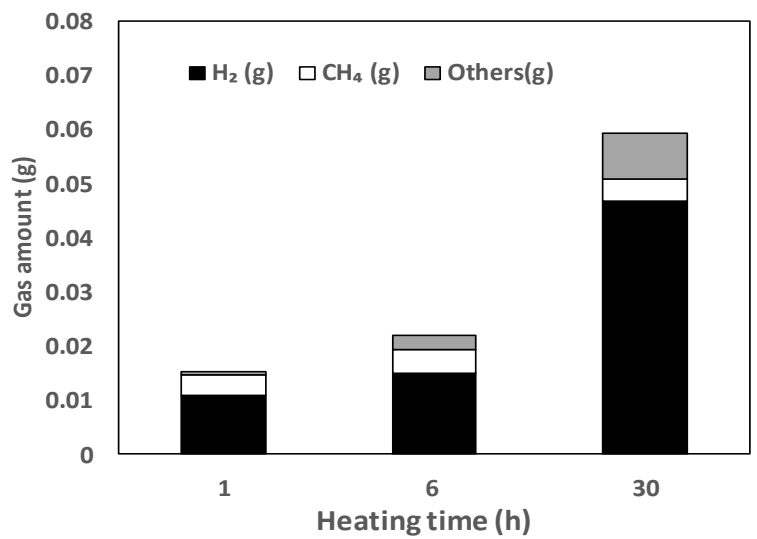

Fig. 9. Production gas after the pyrolysis with addition of $\mathrm{NaOH}$ for various heating times.
Fig. 10 shows $\mathrm{SiO}_{2}$ content extracted from the residue after the pyrolysis for various heating times. $\mathrm{SiO}_{2}$ can be extracted from the residue after the pyrolysis with $\mathrm{NaOH}$ for longer than $1 \mathrm{~h}$, and the $\mathrm{SiO}_{2}$ extraction are almost constant (approximately $0.4 \mathrm{~g} / \mathrm{g}$ ).

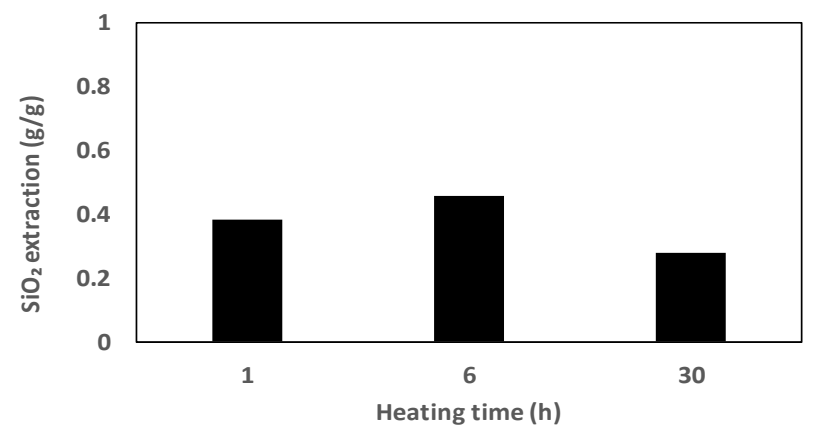

Fig. 10. $\mathrm{SiO}_{2}$ extraction from the residue after the reaction with addition of $\mathrm{NaOH}$ for various heating times.

The residue after 30-h heating is different size particle with brown color, and the weight of the residue and generated gas amount are larger than those for $1 \mathrm{~h}$ and $6 \mathrm{~h}$. The qualitative analysis of chemical composition for the residue after $30-\mathrm{h}$ heating was done by energy dispersive X-ray spectrometry (EDS), and the contents of $\mathrm{Fe}$ and $\mathrm{Cr}$ were confirmed. It would be considered that the material of the reactor was reacted with $\mathrm{NaOH}$. Therefore, the heating time used in this experiment is shorter than $6 \mathrm{~h}$ to avoid the fatigue of the reactor by $\mathrm{NaOH}$.

Fig. 11 shows the photos of the residue after the pyrolysis with $\mathrm{NaOH}$ at various temperatures. The reaction time is 6-h and $\mathrm{NaOH}$ addition is $3 \mathrm{~g}$. At all temperatures, decomposition of both resin and glass fiber was observed (Fig. 11).
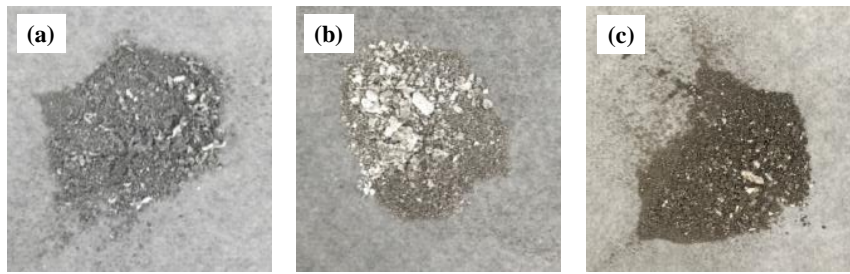

Fig. 11. Residual weight ratios of the residue after the reaction with addition of $\mathrm{NaOH}$ at (a) $400{ }^{\circ} \mathrm{C}$, (b) $500{ }^{\circ} \mathrm{C}$ and $550{ }^{\circ} \mathrm{C}$.

Fig. 12 shows the residual weight ratio of the pyrolysis at various temperatures. At all temperatures, the residual weight is almost $20 \%$ of raw sample.

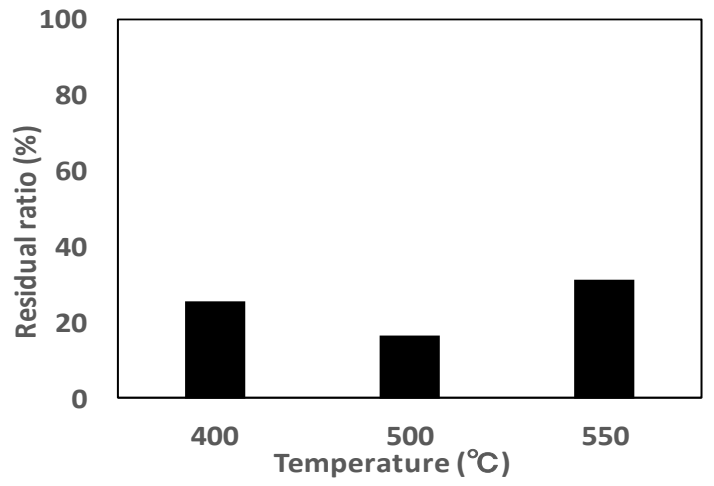

Fig. 12. Residual weight ratios of the residue after the reaction with addition of $\mathrm{NaOH}$ at various temperatures. 
Fig. 13 shows the product gas by pyrolysis with $\mathrm{NaOH}$ addition at various temperatures. Regardless of reaction temperatures, production of hydrogen gas and methane gas was confirmed by pyrolysis with sodium hydroxide. A larger amount of methane and hydrogen gases can be generated, with increasing the reaction temperature.

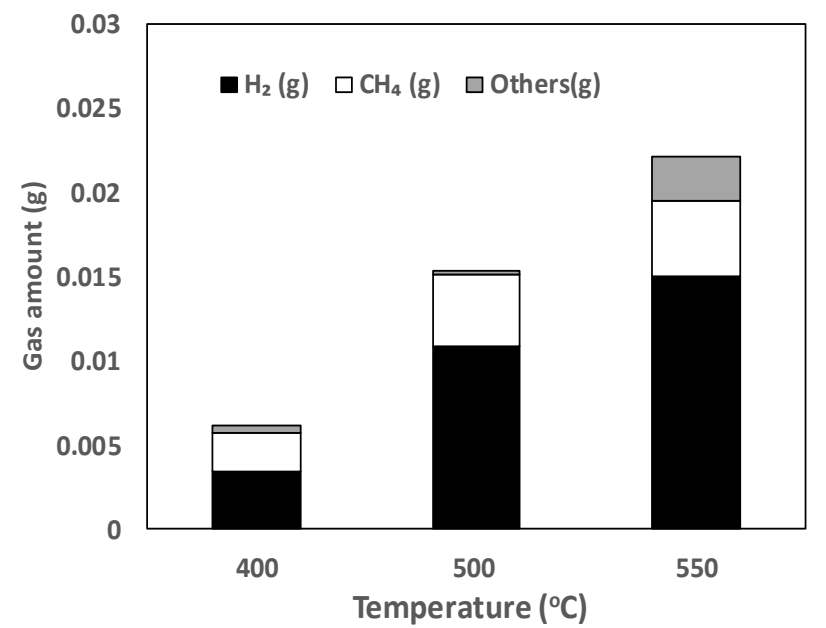

Fig. 13. Product gas during the pyrolysis with addition of $\mathrm{NaOH}$ at various temperatures.

Fig. 14 shows $\mathrm{SiO}_{2}$ content extracted from the residue after the pyrolysis at various temperatures. $\mathrm{SiO}_{2}$ can be extracted from the residue of the pyrolysis with $\mathrm{NaOH}$ above $400^{\circ} \mathrm{C}$, and the amount of extracted $\mathrm{SiO}_{2}$ content was approximately $0.4-0.5 \mathrm{~g} / \mathrm{g}$.

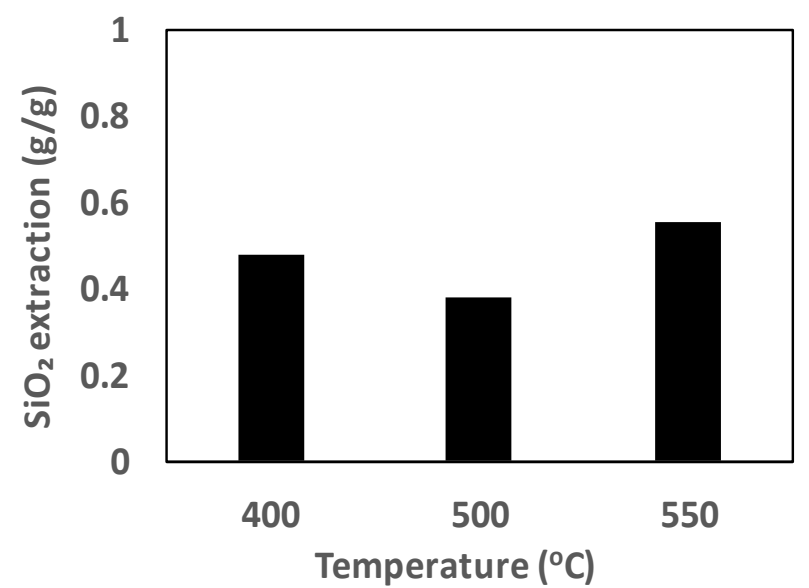

Fig. 14. $\mathrm{SiO}_{2}$ extraction from the residue after the reaction with addition of $\mathrm{NaOH}$ at various temperatures.

From these results, waste glass wool insulator can be decomposed by the pyrolysis with $\mathrm{NaOH}$ above $400{ }^{\circ} \mathrm{C}$ for 1 $-6 \mathrm{~h}$.

Fig. 15 shows the XRD patterns of (a) after pyrolysis and (b) after $\mathrm{SiO}_{2}$ extraction. The pyrolysis condition is that $\mathrm{NaOH}$ addition is $3 \mathrm{~g}$, the heating time is $1 \mathrm{~h}$, and the reaction temperature is $550{ }^{\circ} \mathrm{C}$. After pyrolysis with $\mathrm{NaOH}$, sodium silicates, such as $\mathrm{Na}_{23} \mathrm{Al}_{23} \mathrm{Si}_{25} \mathrm{O}_{96}, \mathrm{Na}_{4} \mathrm{SiO}_{4}, \mathrm{NaAlSiO}_{4}$ and $\mathrm{Na}_{2} \mathrm{SiO}_{3}$, were formed due to the reaction between glass fiber in insulator and added $\mathrm{NaOH}$, and these are dissolved into nitric acid to be extracted to remain calcite which included in resin for filler. It may be considered that the obtained residue can be used for raw material for cement.

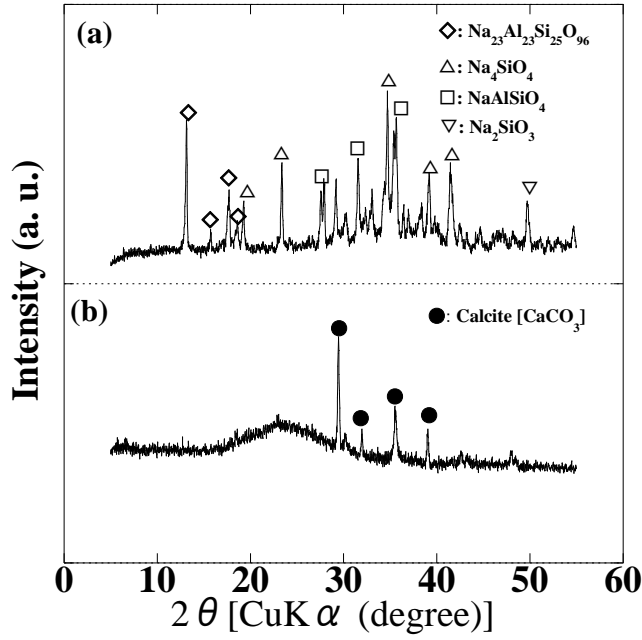

Fig. 15. XRD patterns of (a) after pyrolysis and (b) after $\mathrm{SiO}_{2}$ extraction.

\section{CONCLUSION}

In this study, we attempted to decompose waste insulator using pyrolysis with sodium hydroxide. By using pyrolysis with sodium hydroxide, waste insulator can be decomposed by correcting the resin into the gases, such as hydrogen and methane, and glass fiber into soluble salt in order to be extract into the solution.

\section{REFERENCES}

[1] Y. Yamamoto, K. Iino, and H. Taira, "Development of recycling equipment for glass wool waste," Taiyo Nippon Sanso Technical Review, no. 23, pp. 61-66, 2004.

[2] S. Ogawa and T. Uematsu, On-site Technology for Glass Production, Glass Manufactures Association of Japan, Tokyo, 1993.

[3] Z. Z. Hlaing, T. Wajima, S. Uchiyama, and H. Nakagome, "Reduction of bromine compounds in the pyrolysis oil of computer casing plastics using shell, $\mathrm{Ca}(\mathrm{OH})_{2}$ and $\mathrm{NaOH}, "$ APCBEE Procedia, vol. 10, pp. 193-197, 2014.

[4] T. Wajima, Z. Z. Hlaing, A. Saito, and H. Nakagome, "Removel of bromine from pyrolysis oil with $\mathrm{NaOH}$ in a reflux condenser system," Journal of Multidisciplinary Engineering Science and Technology, vol. 2, no. 5, pp. 1201-1204, 2015.

[5] T. Wajima, Y. Ikegami, K. Yoshizuka, and T. Hirai, "Synthesis of zeolitic material from waste sandstone cake using alkali fusion," Journal of Ion Exchange, vol. 18, no. 4, pp. 142-145, 2007.

[6] T. Wajima and Y. Ikegami, "Effect of a chelating agent on the synthesis of zeolitic materials from waste sandstone cake using alkali fusion," Ars Separatoria Acta, vol. 5, pp. 76-87, 2007.

[7] T. Wajima and Y. Ikegami, "Synthesis of crystalline zeolite-13X from waste porcelain using alkali fusion," Ceramics International, vol. 35, no. 7, pp. 2983-2986, 2009.

[8] T. Wajima and K. Sugawara, "Material conversion from various incinerated ashes using alkali fusion method," International Journal of the Society of Materials Engineering for Resources, vol. 17, no. 1, pp. 47-52, 2010

[9] T. Wajima and K. Munakata, "Conversion of waste sandstone cake into crystalline zeolite X using alkali fusion," Materials Transactions, vol. 51, no. 5, pp. 849-854, 2010.

[10] T. Wajima and K. Munakata, "Conversion of waste sandstone cake into crystalline zeolite X using alkali fusion," Materials Transactions, vol. 51, no. 5, pp. 849-854, 2010.

[11] K. Oya, T. Wajima, and A. Shibayama, "Synthesis of a hydrocalumite-type compound from steel converter slag using alkali fusion," Journal of Ion Exchange, vol. 21, no. 3, pp.185-188, 2010.

[12] T. Wajima and K. Munakata, "Material conversion from waste sandstone cake into cation exchanger using alkali fusion," Ceramics International, vol. 38, no. 2, pp. 1741-1744, 2012.

[13] T. Wajima, "Synthesis of zeolite from blast furnace slag using alkali fusion with addition of EDTA," Advanced Materials Research, vol. 1044-1045, pp. 124-127, 2014. 
[14] T. Wajima, "Alkali fusion synthesis of zeolitic materials from waste dehydrated cake discharged from recycling of construction waste soil," Natural Resources, vol. 8, pp. 300-305, 2017.

[15] S. Onishi, T. Wajima, T. Imai, and S. Sano, "Alkali fusion process of waste stone dust to synthesize faujasite using rotaly kiln," Mechanics, Materials Science \& Engineering Journal, vol. 9, no. 1, pp. 287-292, 2017.

[16] D. Kasahara and T. Wajima, "Material conversion of waste aluminoborosilicate glass into faujasite-type zeolite using alkali fusion," International Journal of Engineering Research and Science, vol. 4, no. 11, pp. 30-36, 2018.

[17] T. Wajima, "Decomposition of mould resin in spent capacitors by $\mathrm{NaOH}$ for the recovery of tantalum," International Journal of Environmental Science and Development, vol. 8, no. 4, pp. 285-289, 2017.

[18] K. Baba and T. Wajima, "Recycling technology of fiber-reinforced plastics using sodium hydroxide," Mechanics, Materials Science \& Engineering Journal, vol. 9, no. 2, pp. 150-155, 2017.

[19] K. Nakaaze and T. Wajima, "A novel recycling technology of bamboo using $\mathrm{NaOH}$," Journal of Engineering and Science Research, vol. 2, no. 5, pp. 7-12, 2018.

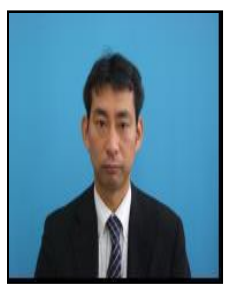

Takaaki Wajima was born in February 1976 in Saga Prefecture, Japan. He has been an associate professor in the Department of Urban Environment Systems, Graduate School of Engineering, Chiba University, Japan, since 2013. He received his bachelor's degree and master's degree in resource engineering from Kyoto University, Japan, in 1998 and 2000, respectively, and his Ph.D in environmental mineralogy and technology from Kyoto University, Japan, in 2004. His main PhD research theme was "micro-porous materials synthesized from paper sludge ash at low temperature, and its chemical mineralogy." In 2004, he moved to the Institute of Ocean Energy at Saga University to work as a postdoctoral researcher, and from 2007 to 2013 he was an assistant professor at Akita University, Japan. His main research interests are waste recycling, resource recovery, and environmental purification. 